\title{
Implementation of Mobile Voting Application in Infrastructure University Kuala Lumpur, Malaysia
}

\author{
Kamaluddin Yahaya Yakubu \\ World Health Organization (WHO, Nigeria)
}

\begin{abstract}
The advancement in technology has transformed the way a lot of processes such academic, social, business and governmental are being carried out. Voting, which is a form of choice exercised by people is not an exception. Technology has been used to transform it from a manual paper-based system to an electronic system and the most recent which is mobile voting system. Infrastructure University Kuala Lumpur Students Representative Council (SRC) is a council that represents student interests in the management of the university. The council conducts elections for students to come and choose their representatives. It is currently using manual paper-based voting to conduct elections which is insecure, inefficient, prone to errors and malpractices and time consuming. This paper proposes the adoption of an Androidbased Mobile Voting Application by the council that will enable students to cast their votes and track the results in real time. The application will also provide candidates with a centralized platform to campaign and attract voters. Rapid Application Development (RAD) methodology has chosen for the development of the application.
\end{abstract}

\section{Keywords}

Voting System, Mobile Voting, Technology, Students Representative Council, Students

\section{INTRODUCTION}

The term voting is understood to be the form of choice. This form of expression can be performed through the ballot, or by any other electoral schemes. Votes are cast to people to people who are contesting for one position or the other, or when people need to be selected for some other purposes. People undergo through different phases when contesting for a position manually; they register formally with the voting board; prepare their agenda and campaign to the voters; undergo the paper-based voting at the stated time. Votes are then sorted, counted and the winners are announced. Records are then documented manually which can be easily lost or manipulated.

Infrastructure University Kuala Lumpur Students Representative Council (SRC) is a council that represents student interests in the management of the university. The council forms part of a broader students' association which cater for students' welfare, societies, entertainments, sports and academic concerns. SRC conducts elections yearly whereby interested candidates stand for position and pursue the students to come and vote for them to occupy certain positions. The contestants campaign to attract voters using posters, letters, face-to-face contact, phone calls and text messages. On the elections day, the students cast their votes for their preferred candidates and the votes are sorted, counted, and the winners emerge. All these processes are carried out manually. This is very inefficient and time consuming, and is subject to malpractice. This consequently leads to poor voter turnout due to the fact that the system in place is not convenient for most students.

In view of this, an Android-based Mobile Voting Application is proposed for IUKL Students Representative Council (SRC) to adopt for its elections. This application will enable the students to cast their votes online and track the results in real time, provide candidates with a centralized platform to campaign, as well as an interactive platform between the candidates and the voters. This will transform the paper-based voting system currently in place to a mobile system.

\section{PROBLEM STATEMENT}

- The current voting system used by SRC is insecure and prone to error.

- The voting process currently is very slow and time consuming.

- Contestants do not have a centralized platform to campaign their ideas easily to students.

- Students cannot track the voting process in real time within the allocated voting time.

- Voters do not get to know the final voting result on time.

\section{OBJECTIVES}

- Provide an Android-based mobile voting system to enhance current voting process.

- Provide a centralized campaign platform for participating candidates.

- Generate automated voting results in real time.

- Present voting results in graphical mode for easy tracking and monitoring.

\section{LITERATURE REVIEW}

Voting is a process at the heart of a democratic society. Voting schemes have evolved from counting hands in early days, to systems that include paper, punch card, mechanical lever, and optical-scan machines [1]. While modern societies fully rely on ICT for business, work and leisure time activities, the use of ICT for democratic decision making is still in its infancy. In fact, the out date technological concepts for voting have been blamed in part for lost and uncounted votes and could therefore be responsible for biased political decisions making [2].

Traditionally, voting process is organized in centralized or distributed manner called voting booths. The earlier process of the election system was quite complex and time consuming. People were waiting in queue for long time [3]. Moreover, the traditional way of voting generates mores constraints; election fraud could be prevented by using physical security measures, audit trails, and observers representing of all parties involved. But the prevention of election fraud is made more difficult by the frequent requirement that votes remain private [4]. Another drawback with the traditional voting system is the absenteeism of voters during the elections as most of voters are busy in their 
workplaces while some voters may be living far away from voting center. Some voters do not like to wait in queues which encourages lack of participation as well. These problems consequently affect the percentage of the votes cast and the outcome is subsequently affected [5].

But with the advancement of technology and its integration into virtually all aspects of human's activities nowadays, an effort has been made to transform voting from the traditional method to an advanced one. This transformation has taken several phases but all under the term Electronic Voting (EVoting). An Electronic voting (E-voting) system is a voting system in which the election data is recorded, stored and processed primarily as digital information. E-voting may become the quickest, cheapest, and the most efficient way to administer election and count vote since it only consists of simple process or procedure and require a few workers within the process [6]. It is a type of voting that includes the use of a computer rather than the traditional use of ballot at polling centers or by postal mail. It encompasses various types of voting: kiosks, the Internet, telephones, punch cards, and mark sense or optical scan ballots. All these types of E-Voting have shown an accurate and speedy performance [7]. E-voting is able to provide convenient, less expensive, fast and secure facilities. Important basic properties of electronic voting are fairness, privacy, eligibility, receipt-freeness, coercionresistance and verifiability [8].

As technology keeps advancing in terms of both hardware, software, and operating systems which has made a lot of things easier, it has become imperative to making voting easier hence, the introduction of mobile voting systems. Mobile Voting System (MVS) is a very secure, efficient and easy way to casting of vote. It is an online voting system that operates in parallel with the existing manual and automated voting processes. It enables the legitimate voters to cast their vote remotely using their mobile devices. It does not require the voters to appear at the polling station and this helps to alleviate the nuisance of long queues at the poll sites which wastes voters' time. It also eases the counting process as votes are counted instantly the votes are cast and the result is displayed. Occasionally, graphical display will be available on the site attached to the system for all stakeholders to view their progress and hence ensuring transparency [3].

The main reason behind the tremendous development in android application development is that the android is an open source operating system. It means that the software developers can have customization rights. As well as the software development kit provides tools to build and run android applications. Almost $90 \%$ of the people around the globe are aware of the technology and use it in their daily life [9]. Innovating new and better voting systems is a field of great interest as elections are an integral part of a democracy and our community [10]. However, Electronic voting which includes mobile voting systems may offer advantages disadvantages exist as well including the potential for flaws or weakness in any electronic component [11]. Compared to other voting, mobile voting system appears to be the best because of its ease of use. Therefore, this paper discusses a mobile voting system in a tertiary institution for students' use.

\section{METHODOLOGY}

Rapid application development (RAD) has been chosen to develop this application. RAD is a software development methodology that uses minimal planning in favor of rapid prototyping. In RAD model, the functional modules are developed in parallel as prototypes and are integrated to make the complete product for faster product delivery. RAD can be divided into four main part Requirements Planning, User Design, Construction and Cut over Phase. Using this model, it gives advantage to the voting application such as reduced development time by encouraging customer feedback and quick reviews, and is also very flexible for scope changes. This will create a better advantage of implementing the system that works based on the user requirements and within cost. Object-Oriented Technique has been chosen as the development technique by using Unified Modelling Language (UML) diagrams to illustrate the requirements of the application. The application has three (3) users namely:

- Voter: This is an IUKL student who can use the application to cast vote.

- Candidate: This is an IUKL student who is contesting for a position in the Students' Representative Council.

- Administrator: This is an IUKL staff normally from the Students Affairs Division who will handle the system.

\subsection{Functional Requirements}

These are the major functionalities the system is expected to provide to the users. In this system, the functionalities of the system are that it shall:

- Allow students to register as voters

- Allow the admin to verify and approve registration of users

- Allow the admin, voters and candidates to login

- Allow the admin to manage election events

- Allow Admin to generate report

- Allow candidates to campaign to voters

- Allow candidates and students to cast votes

- Allow candidates and students to give feedback

- Allow users to view elections results in real time

- Display elections results in a graphical fashion

The use case diagram below illustrates the users and the functionalities of the proposed application: 


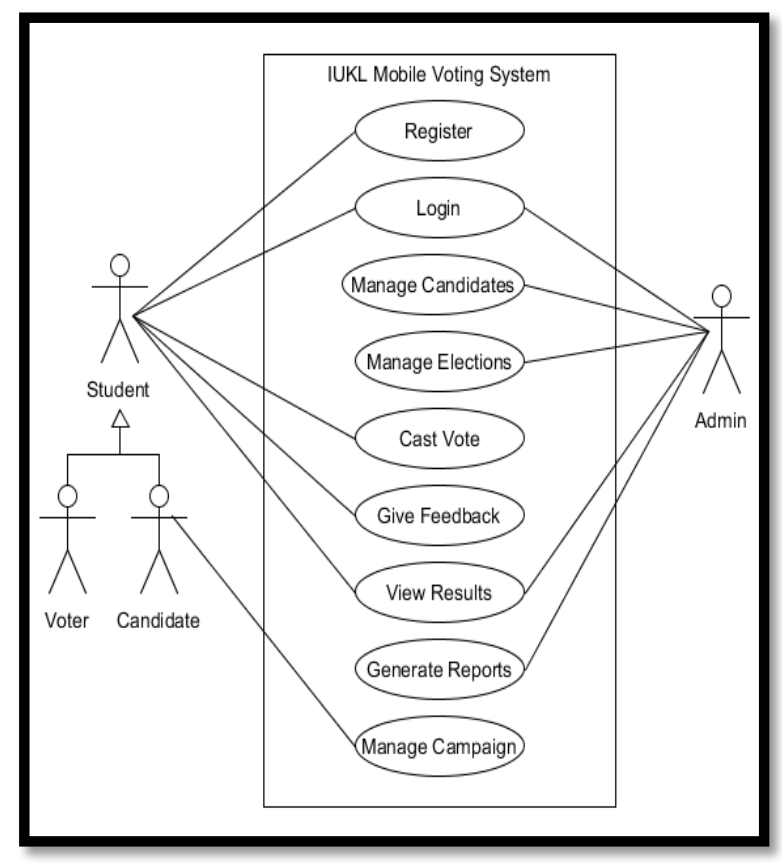

Fig 1: Use Case Diagram

\section{IMPLEMENTATION}

System development deals with the real implementation of the system so that it will be operational. The system has been developed using Android Programming (Java) at the frontend, and PHP at the back-end, with MySql as the database. This section describes the user interfaces and illustrates how the system will work. To differentiate and authenticate users, each the user must login before any activity using the system can be executed. However, the system offers a few functions before login (i.e. registrations, helping users to acquire a new password if the initial one has been forgotten etc.). Once a user has logged in, the home page will be displayed which look differently, depending on the user category.

\subsection{The System Modules and Functions}

This sections portrays the functionalities provided by the system after implementation.

\subsubsection{Sign Up Page}

The Sign Up page is the user registration page where a user needs to fill in all the fields in the form to be a system user. After the form has been filled and submitted, the admin will receive the details of the new user as a request from where the registration will be approved or disapproved. Upon approval by the Admin, an email will be sent to the new user as a notification of successful registration.

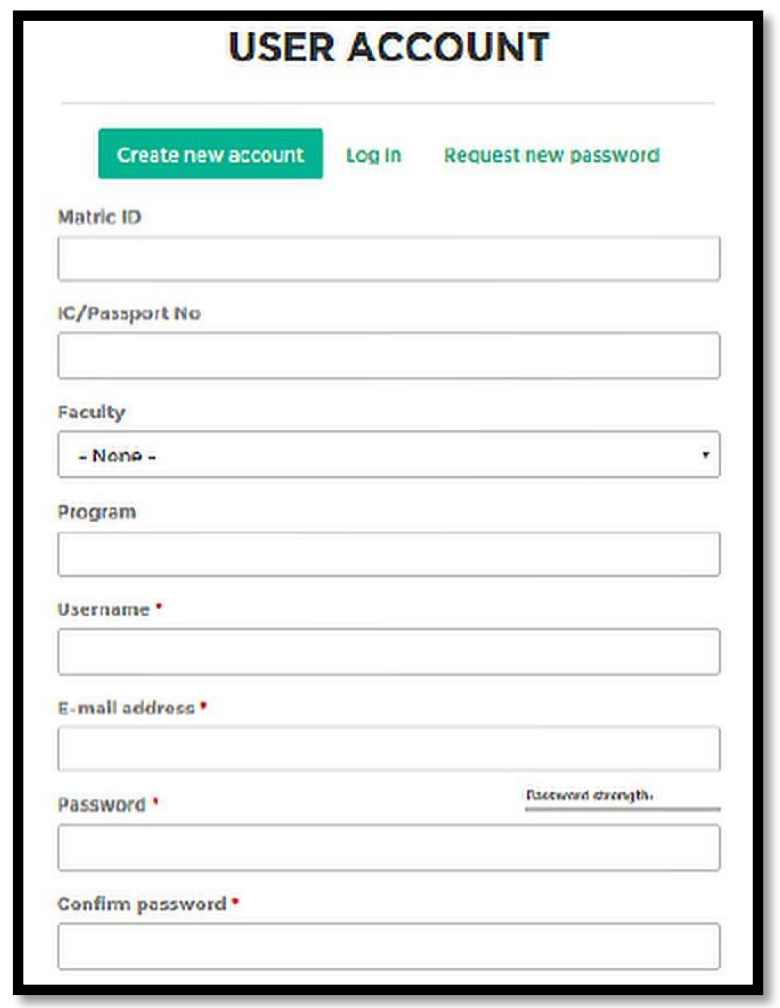

Fig 2: Sign Up Page

\subsubsection{Login Page}

Login page is the page that allows registered users to get access to their own created accounts. This page has the same functionalities for all users only that each user has his/her own different combination of username and password. Username for each user must be unique (Username or Student ID).

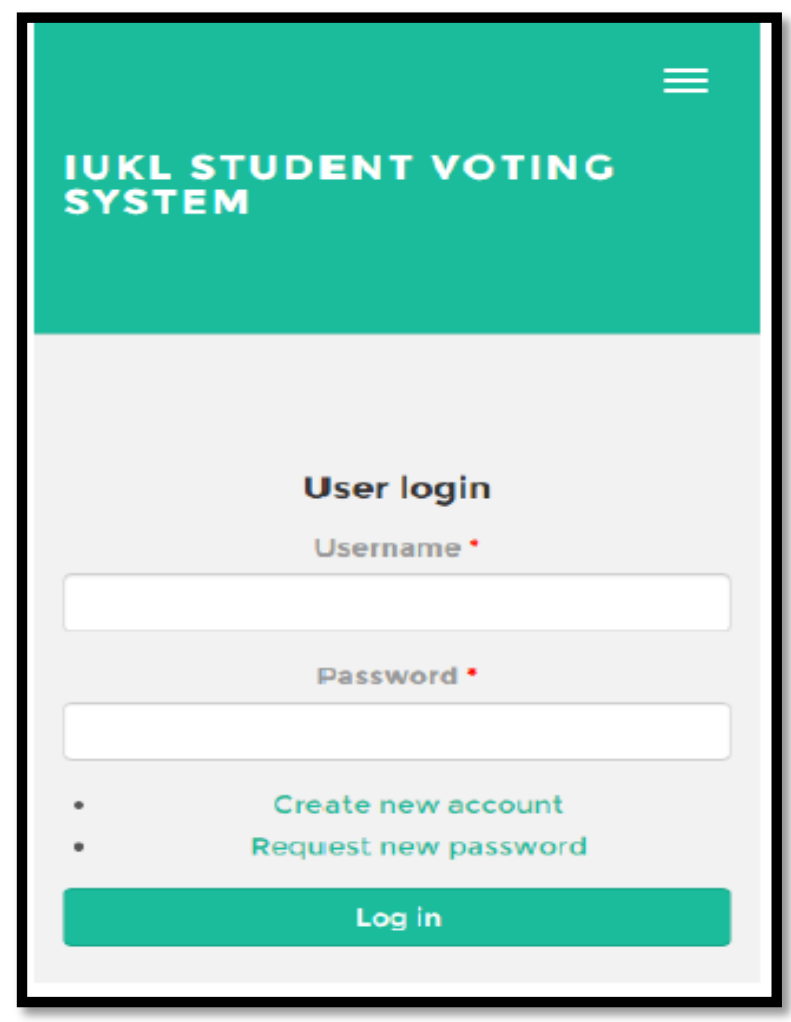

Fig 3: Login Page 


\subsubsection{Election Page}

This page contains the details of election event. It is operated on two sites, the normal user site who uses the application on an Android device and the Admin site who operates on a normal PC. The admin manages the election event and users view the details.

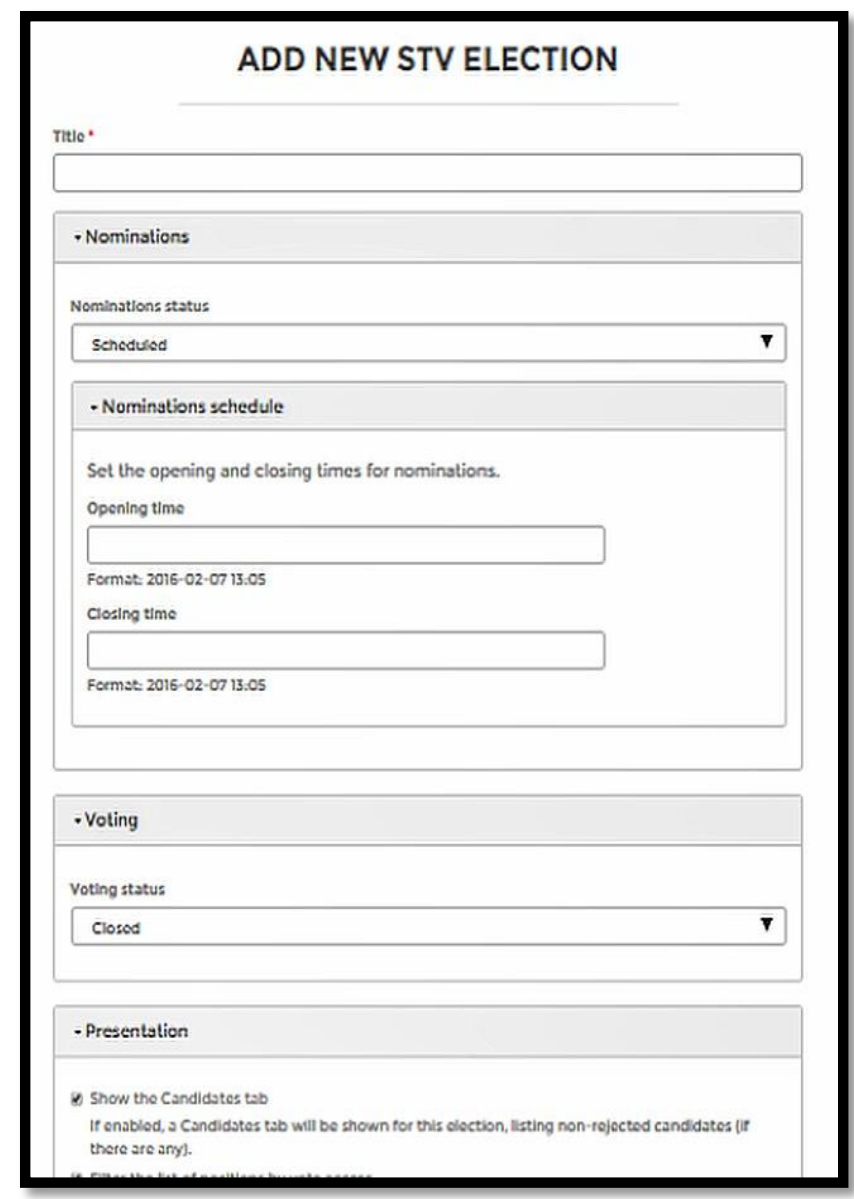

Fig 4: Create New Election Page

\subsubsection{Position Page}

This page enables the Admin to create the individual positions that are open for contest.

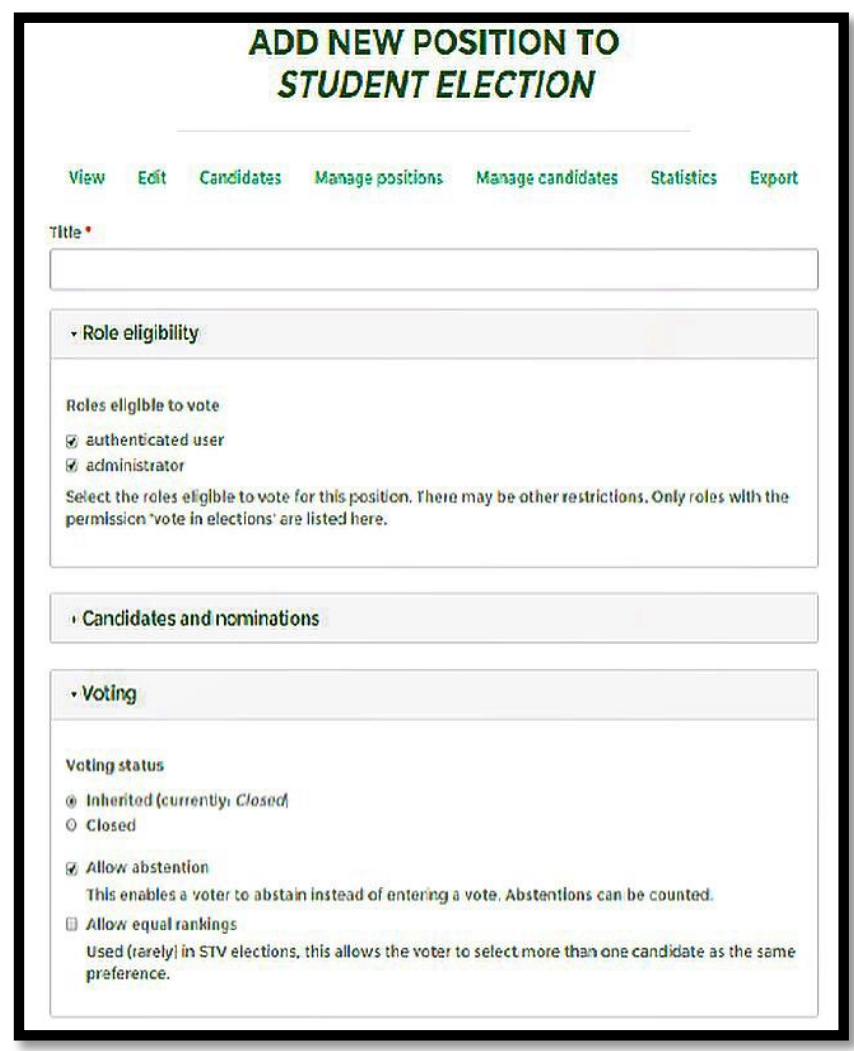

Fig 5: Create Position Page

\subsubsection{Register Candidate Page}

This page enables the Admin to register the individual candidates under the positions they are contesting for.

\section{ADD NEW CANDIDATE TO PRESIDENT}

\section{View Edit Results}

Position *

Presidont

Name ${ }^{*}$

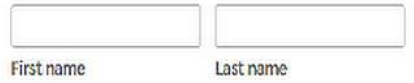

E-mail address

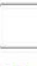

Status $\cdot$

Hopeful

Associated user account

dev

จ Published

When published, candidates can be viewed by those who are allowed to view the election.

Save Cancel

Fig 6: Register Candidate Page 


\subsubsection{View Candidates Page}

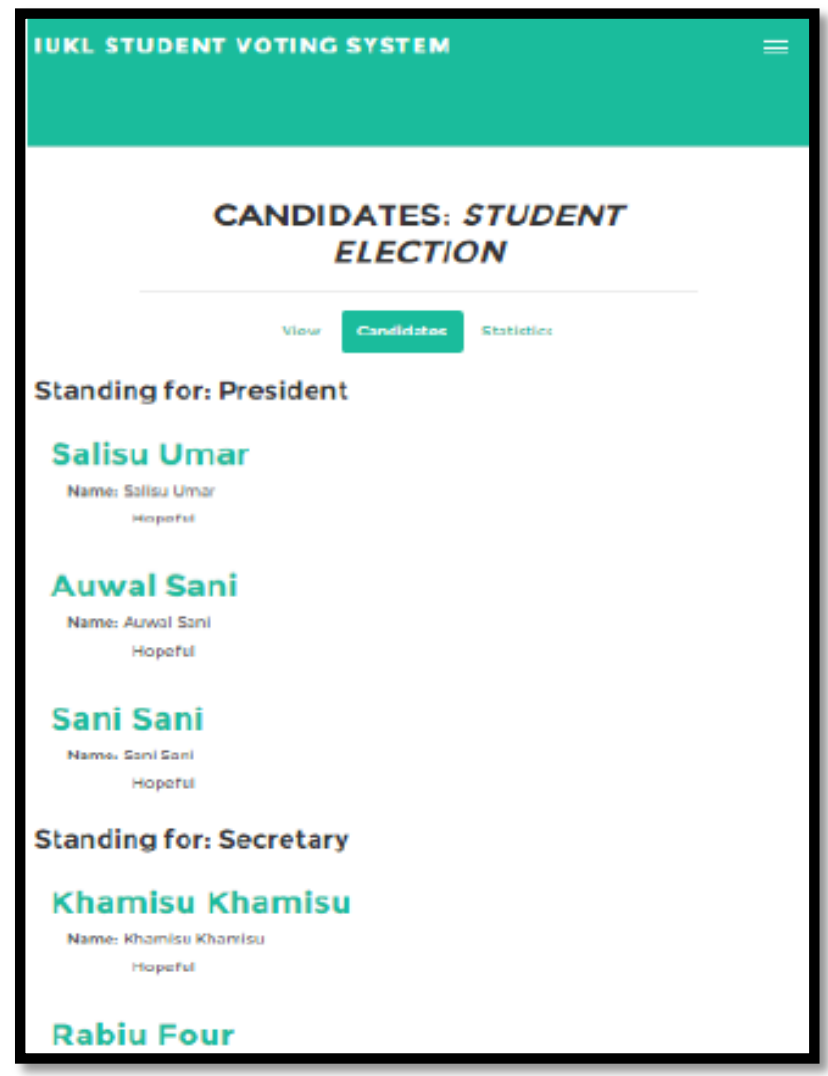

Fig 7: View Candidates

\subsubsection{Manifesto Page}

This page enables the candidates to create their manifestos and share with the other uses of the system.

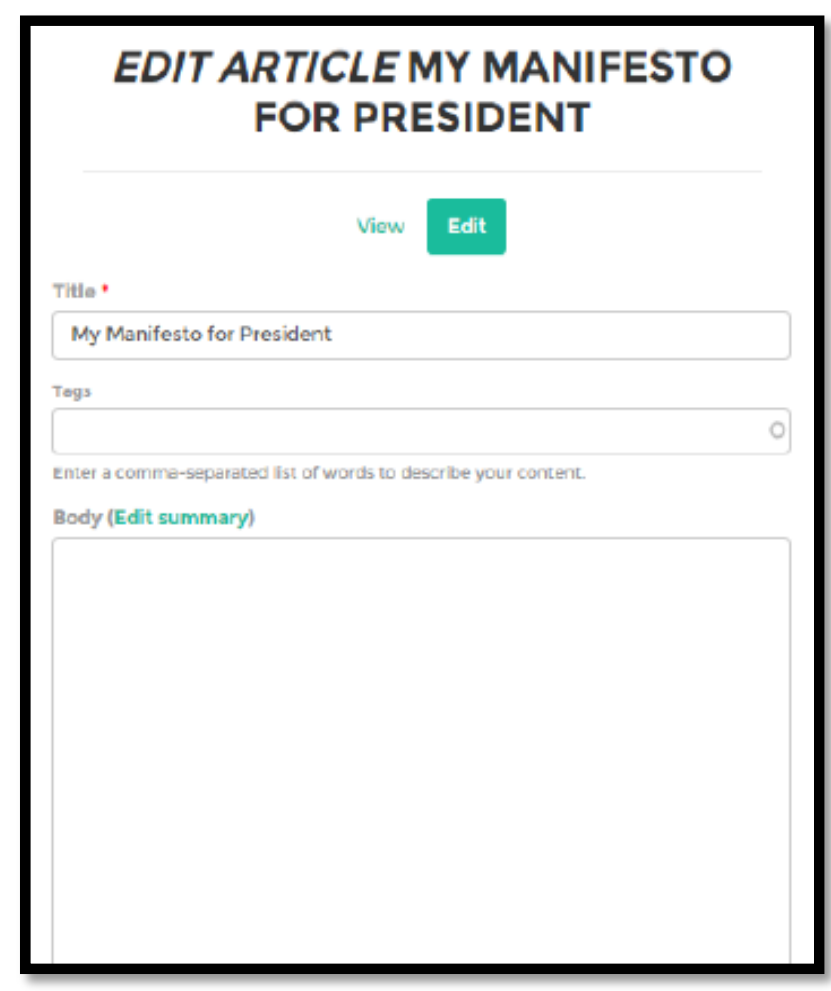

Fig 8: Create Manifesto Page

\subsubsection{Voting Page}

Voting vote page is the page that permits the voters to cast votes to their chosen candidates. Casting vote is in accordance with the different positions. The positions are voted for accordingly one after the other. The voting is in preference order. This gives the voter the privilege to choose his candidates on preference that if the first preference does not win, then the second one and so on.

\section{VOTE: PRESIDENT}

The following candidates are standing for the position President (1 vacancy).

\section{Yourlballot paper}

Please rank the candidates according to your preference. Candidates are displayed in a random order.

\begin{tabular}{l|l|}
\hline Name & Preference \\
\hline Sani Sani & Nopreference \\
\hline Auwal Sani & No preference \\
\hline Salisu Umar & No proforonce \\
\hline
\end{tabular}

Cleariform

Fig 9: Voting Page

\subsubsection{Elections Result Page}

This page contains the details of the election. This is tracked in real time during the voting until it is completed. The result is displayed in tabular form in respect of the different positions. Each position has its table which contains the names of the candidates, their registration ID, total votes they have gotten and the percentage out of the total votes. 


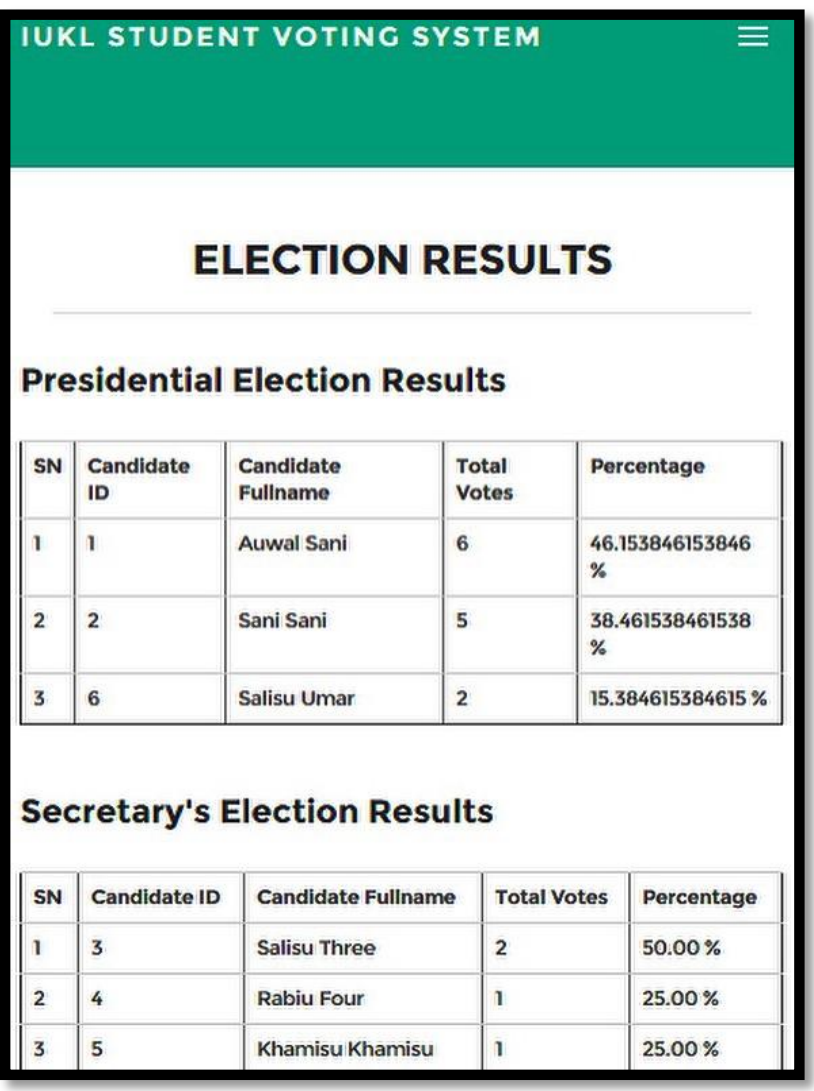

Fig 10: Election Result

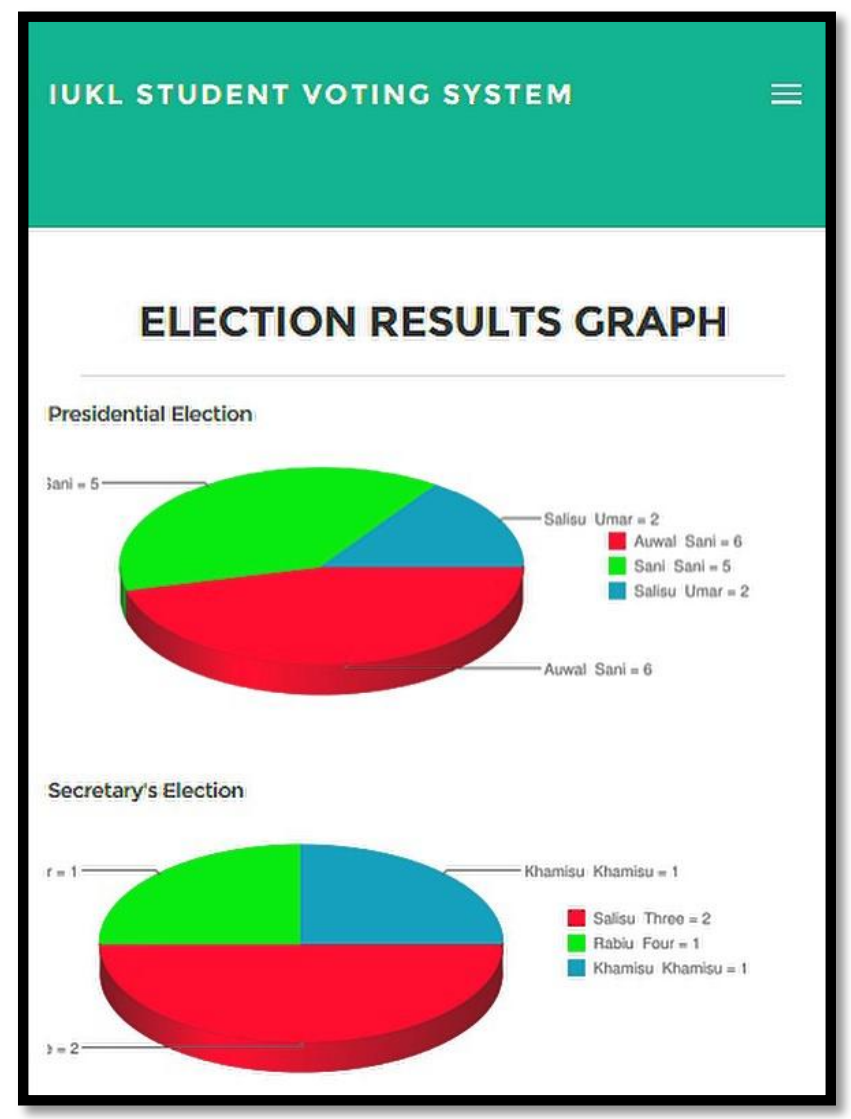

Fig 11: Election Result (Graphical)

\section{SYSTEM TESTING}

Testing is carried out to evaluate whether the system and its components satisfy the requirements already specified. It is done to establish confidence and provide information about the quality of the system (product or service) under test to the stakeholder (users). Black Box Testing has been carried out on this application and the result obtained that the system is working perfectly.

For the user site, testing has been done on the Android phone, Blackberry, iOS and Windows which finally shows that the application can only run Android phone. For the Admin site, testing has been done between different browsers wish is Google Chrome, Internet Explorer, Firefox, and Safari and also between two different type of operating system which Mac OSX and Widows $7 / 8$ in order to make sure that the product meets it requirement so that to deliver a quality product. Some of the defects has been point out and fixed. The errors observed were corrected.

Different Operating Systems were also used which finally showed that the system runs $100 \%$ on each OS used. To round up, the system has shown a greater response to the test cases and can be said to have achieved its target

\section{CONCLUSION}

IUKL Mobile Voting Application has been successfully developed and tested locally and on the cloud. The methodology specified has been followed duly in the development of the system and more importantly, the set objectives have been achieved. Proper security algorithms have been used to make sure that to a certain degree, the system provides a good security to the users.

Moreover, a user can only vote once which is a great accomplishment. By using the system, the Students Council will observe a more transparent, credible, and free and fair elections. Campaigns and setting up election schedules have been made easier by the system.

However, different users use different mobile platform. Therefore, future development should focus on developing a better system that will operate on different platforms such as iOS, Blackberry and Windows.

\section{REFERENCES}

[1] F. A. Haziemeh, M. K. Khazaaleh and K. M. Al-Talafha, "New Applied E-Voting System," Journal of Theoritical and Applied Information Technology, Vol. 25, Num 2,8645 ISSN 1992, pp. 88-97, 2011.

[2] M. Mohit, M.Karthik, T.Rajavel and M. J.Sangeetha, "EVoting System Using Android Application," International Journal of Research in Engineering \& Advanced Technology, Volume 2, Issue 2, ISSN: 2320 8791, pp. 1-5, 2014.

[3] S. Anamica and J. Jayavel, "Mobile Device Based Voting System Using the Visual Cryptography," International Journal of Novel Research in Computer Science and Software Engineering, Vol. 3, Issue 1, ISSN 2394-7314, pp. 210-214, 2016.

[4] G. Manjunath, N. Sreenivas, Y. Abate and T. A. Weseni, "Mobile e-Voting Service for $\mathrm{m}$-Governance in Ethiopia," International Journal of Innovative Research in Computer and Communication Engineering, Vol. 3, Issue 5, pp. 3702-3707, 2015.

[5] D. R. Gawade, A. Shirolkar and S. R. Patil, "E-Voting System Using Mobile SMS," International Journal of Research in Engineering and Technology, Volume: 04 
Issue: 09, eISSN: 2319-1163 | pISSN: 2321-7308, pp. 188-192, 2015

[6] Al-Ameen and S. Talab, "The Technical Feasibility and Security of E-Voting," The International Arab Journal of Information Technology, Vol. 10, No. 4, , pp. 397-404, 2013.

[7] M. Hajjar, B. Daya, A. Ismail and H. Hajjar, "An EVoting System for Lebanese Elections," Journal of Theoretical and Applied Information Technology, , pp. 21-29, 2006.

[8] H. N. Oo and A. M. Aung, "Implementation and Analysis of Secure Electronic Voting System," International Journal of Scientific \& Technology Research Volume 2, Issue 3, ISSN 2277-8616, pp. 158161, 2013.
[9] R. S. Rajashree, J. V. Bhagyashree, A. A. Akshay, G. R. Manoj and M. D. Phalke, "Literature Survey on Secure Mobile Based E-Voting System," International Journal of Computer Science and Information Technology Research, Vol. 3, Issue 4, ISSN 2348-1196 (print), ISSN 2348-120X (online), pp. 234-236, 2015.

[10] M. A. Hegde, M. C. Anand and M. J. B, "Mobile Voting System," International Journal of Science, Engineering and Technology Research (IJSETR), Volume 6, Issue 4, pp. 741-745, 2017.

[11] F. Ahmad, M. Rafay and K. Haider, "MOBILE VOTING SYSTEM," International Journal of Computer Science and Mobile Computing, IJCSMC, Vol. 7, Issue. 1, p. 1317, 2018.

[12] 